\title{
Survey of asthma deaths in the Northern region, 1970-85
}

\author{
H J Fletcher, S A Ibrahim, N Speight
}

\begin{abstract}
Thirty five asthma deaths in children aged 1 to 16 years were investigated in detail. Twenty four of these children had previously been under hospital consultant care and there were seven inpatient deaths. Twenty nine cases $(83 \%)$ had a history of severe asthma, 17 of whom had previously experienced a life threatening attack. The fatal outcome, however, could not have been predicted in six children $(17 \%)$ with preceding mild asthma. Potentially preventable factors in management were found in 28 cases $(80 \%)$. While 18 $(51 \%)$ had been chronically undertreated, the major factor in 20 deaths (57\%) was suboptimal management of the final attack owing to delay in seeking medical attention, inadequate medical response, or both. Only two children had received systemic corticosteroid in appropriate amounts during the final illness.

If mortality is to be reduced, families of asthmatic children must be educated to recognise severe symptoms and be given an appropriate 'crisis plan'. Hospitals should permit free access and have a clear protocol for the management of children with severe asthmatic attacks.
\end{abstract}

Asthma affects approximately $10 \%$ of the childhood population. It carries a small mortality which, despite therapeutic advances during the past two decades, has not declined significantly. Studies in adult asthmatics have shown repeatedly that around $80 \%$ of deaths occurred as a result of poor patient education, supervision, and management. ${ }^{12} \mathrm{~A}$ recent New Zealand survey on childhood asthma deaths suggested that they were largely preventable. ${ }^{3}$ In this country, similar conclusions were drawn by Carswell in his review of 30 childhood asthma deaths. ${ }^{4}$ More than half of the children he studied died before 1970, however, and the detailed circumstances of many of the deaths were not investigated. This study of childhood asthma deaths in the Northern region explores whether such deaths were predictable or preventable.

\section{Subjects and methods}

Names of children aged 1 to 16 years inclusive, who were certified as having died of asthma in the period between January 1970 and December 1985, were obtained from the Office of Popula- tion Censuses and Surveys (OPCS). All had resided in the area covered by the Northern health region, which includes the counties of Northumberland, Cumbria, Durham, Cleveland, and Tyne and Wear.

Permission was obtained for hospital case notes, coroner's reports, and where possible family practice, school health, and school attendance records to be made available. These were examined in detail. The diagnosis of asthma as a cause of death was based either on a convincing clinical history or findings at postmortem examination. With the approval of the current general practitioner, parents of the deceased children were contacted by letter and those who agreed to participate in the study were interviewed at home (by SAI or HJF). The interviews were conducted between 1985 and 1987. The time between date of death and date of interview ranged from one to 15 years with a median time of seven years.

All the information was then reviewed with particular reference to the following aspects: (i) whether asthma had been diagnosed before death; (ii) education received by families regarding the disease and its management; (iii) detailed circumstances of the final illness; and (iv) the adequacy of the medical management both before and during the final attack (assessed according to accepted standard treatment at the time).

The study was approved by the relevant district ethical committees.

Forty six recorded asthma deaths were obtained from OPCS of which three were found on further investigation to have died from other causes. One death was reported to us from another source. There were therefore 44 asthma deaths. Postmortem reports were available for 29 of these.

The distribution of deaths over the study period is shown in table 1. During this period, the average annual mortality rate for asthma for children aged 1 to 14 years in the Northern region was calculated to be $0 \cdot 34 / 100000$. This was slightly less than the equivalent figure for England and Wales $(0 \cdot 44 / 100000)$ calculated from OPCS data. ${ }^{5} 6$

The age and sex distribution is shown in table 2. Deaths occurred predominantly in the preschool and adolescent age groups, which was consistent with national data. ${ }^{5} 6$

Time of death was evenly distributed over 24 hours. Half the deaths occurred in the months of June to September. Twenty eight of the 44 
Table 1 Number of recorded deaths in each year of study $(n=44)$

\begin{tabular}{|c|c|c|c|c|c|c|c|c|c|c|c|c|c|c|c|c|}
\hline & 1970 & 1971 & 1972 & 1973 & 1974 & 1975 & 1976 & 1977 & 1978 & 1979 & 1980 & 1981 & 1982 & 1983 & 1984 & 1985 \\
\hline $\begin{array}{l}\text { No of deaths } \\
\text { (No investigated) }\end{array}$ & $4(2)$ & $6(3)$ & $1(0)$ & $2(2)$ & $1(1)$ & $2(2)$ & $1(1)$ & $2(2)$ & $1(1)$ & $3(2)$ & $2(1)$ & $3(3)$ & $2(2)$ & $8(7)$ & $5(5)$ & $1(1)$ \\
\hline
\end{tabular}

Table 2 Age and sex distribution of recorded asthma deaths

\begin{tabular}{lccc}
\hline Age (years) & Boys & Girls & Total \\
\hline $1-4$ & 3 & 11 & 14 \\
$5-8$ & 1 & 3 & 4 \\
$9-12$ & 2 & 4 & 6 \\
$13-16$ & 12 & 8 & 20 \\
\hline Total & 18 & 26 & 44 \\
\hline
\end{tabular}

children died during a weekend (between $6 \mathrm{pm}$ on Friday and 8 am on Monday). Twenty seven deaths occurred at home or elsewhere, five in transit to hospital, and 12 in hospital.

Parents were interviewed in 30 cases. Sufficient information was available from other sources to include five further cases, so that 35 of the 44 deaths were investigated in detail. The nine remaining cases were not investigated because general practitioners considered it inappropriate to contact the families, parents declined to be interviewed, or could not be traced. Most of these had died in the early part of the study period.

\section{Results}

PREVIOUS PATTERN AND SEVERITY OF ASTHMA Twenty four children had developed their first symptoms of asthma before the age of 3 years. Cases were grouped according to the frequency of symptoms during the two years before the final episode as shown in fig 1 .

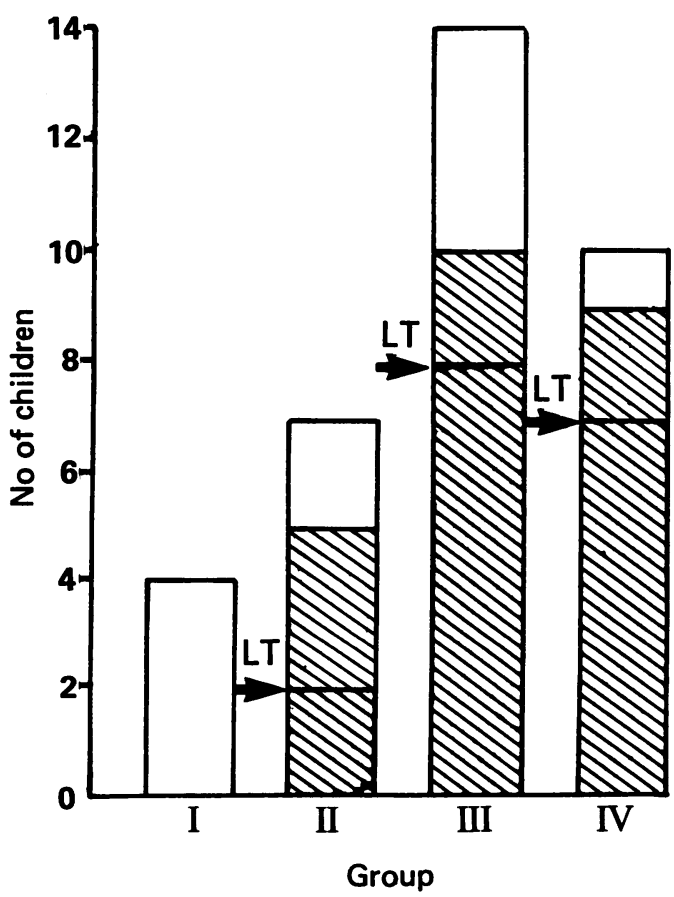

Figure 1 Frequency and severity of wheezing episodes during last two years of life. Group $I,<4$ episodes of wheeze/year; group II, 5 to 12 episodes of wheeze/year; group III, >12 episodes of wheeze/year; and group IV, permanent wheezing. Hatched area represents children permanent wheezing. Hatched area represents children treatment. $\rightarrow T$ indicates the number of children experiencing $\geqslant 1$ life threatening attack.
Severity of the worst previous attack

Twenty four of the 35 children had within the last two years suffered one or more severe attacks that had warranted emergency administration of one or more of the following treatments: intravenous, subcutaneous, or nebulised bronchodilator, and intravenous corticosteroid or oxygen, or both. Seventeen of these cases had suffered one or more life threatening episodes, associated with at least one of the following features: prolonged cyanosis, 'silent chest', pulsus paradoxus, loss of consciousness, cardiorespiratory arrest or documented hypercapnia. These signs were well documented in the hospital case notes of 13 cases and were described by parents or the general practitioner in the remaining four.

\section{Overall severity}

Symptom frequency was not always related to the overall severity of the condition. Taking all factors into consideration, the four cases assigned to group I and two of the seven cases in group II appeared to have had relatively mild symptoms before the final attack. Indeed, two children, aged 22 and 24 months respectively, died during their first severe episode of wheezing, illustrating the unpredictability of this condition in young children. All the remaining children had a history of severe asthma. A substantial proportion of children in groups III and IV had frequent nocturnal wheezing. Six cases in group IV were growth impaired-in one case, secondary to long term corticosteroid treatment.

\section{MANAGEMENT BEFORE THE FATAL ATTACK}

Treatment and control

Table 3 shows the long term treatment prescribed. Control was assessed according to the

Table 3 Routine drug treatment prescribed before onset of final illness $(n=35)$

\begin{tabular}{|c|c|c|}
\hline Age (years) & Drug combination & $\begin{array}{l}\text { No of } \\
\text { children }\end{array}$ \\
\hline$<5$ & $\begin{array}{l}\text { No regular treatment } \\
\text { Antibiotic } \\
\text { Oral bronchodilator } \\
\text { Oral/nebulised bronchodilator plus } \\
\text { nebulised sodium cromoglycate } \\
\text { Oral bronchodilator plus } \\
\text { adrenocorticotrophic hormone }\end{array}$ & $\begin{array}{r}2 \\
1 \\
4 \\
3\end{array}$ \\
\hline$\geqslant 5$ & $\begin{array}{l}\text { No regular treatment } \\
\text { Inhaled bronchodilator } \\
\text { Inhaled bronchodilator plus sodium } \\
\text { cromoglycate } \\
\text { Inhaled bronchodilator plus } \\
\text { beclomethasone } \\
\text { Inhaled bronchodilator plus sodium } \\
\text { cromoglycate plus beclomethasone } \\
\text { Inhaled bronchodilator plus } \\
\text { prednisolone/adrenocorticotrophic } \\
\text { hormone } \\
\text { Inhaled bronchodilator plus } \\
\text { beclomethasone plus prednisolone/ } \\
\text { adrenocorticotrophic hormone }\end{array}$ & $\begin{array}{l}1 \\
5 \\
3 \\
6(3)^{*} \\
4(1)^{*}\end{array}$ \\
\hline
\end{tabular}

${ }^{*}$ Children receiving additional drugs - for example, theophylline or ketotifen. 
following criteria: (i) frequency of attacks and exercise tolerance, according to parental history; (ii) missed schooling, often verified by school attendance records; (iii) peak flow rates where documented; and (iv) number of emergency consultations confirmed by hospital and practice notes. These factors were examined in relation to documented prescribed drug treatment. Allowance was made for the fact that nebulisers for the delivery of both bronchodilators and prophylactic drugs were not freely available until the early 1980s.

Fourteen of the 35 children had been adequately controlled until the onset of the fatal attack. Three children had suffered intractable asthma that responded poorly to all forms of maintenance treatment. The remaining 18 cases were poorly controlled, with the following deficiencies in treatment. (1) Seven children had not been prescribed adequate prophylaxis, and some had only occasional access to a bronchodilator. Antibiotics were frequently prescribed. (2) Four children who were normally well controlled deteriorated during the last two months of life and on medical consultation had been prescribed antibiotics only. (3) Four children, apparently compliant with prescribed treatment, might have benefited from long term systemic corticosteroid. (4) Three further cases had been instructed to stop long term corticosteroid within three months of death and had not been properly followed up.

\section{Supervision}

Nineteen children were attending hospital paediatric outpatient departments. Five cases were under the care of respiratory physicians. General practitioners alone were caring for 11 of the children, seven of whom had sufficiently severe asthma to warrant hospital referral. Frequency and severity of symptoms were often insufficiently documented, and the severity of asthma appeared to have been underestimated in the undertreated cases. Twenty eight of the 35 cases lived within easy reach of a general hospital, but only nine had been offered open access to the hospital ward in the event of a severe attack.

\section{Home nebulisers}

Eight children had been using home nebulisers and had died during the last six years of the study. Four were in their teens and the remainder were aged 7, 5, 3, and 2 years respectively. Nebulisers had been appropriately used in five children with difficult asthma. In the remaining three cases, supervision was poor and there had been frequent over-reliance on this form of treatment.

\section{Family education}

Parents were asked to recall the information they had received regarding their child's asthma during life. Nine sets of parents could recall having been given a proper explanation and specific instructions about the prescribed drugs. None had received written instructions other than information on breathing exercises or house dust mite precautions. In the event of a severe attack, only 13 families had been instructed to obtain medical help promptly. None of the families interviewed recalled being made aware by professionals of the potential danger of a severe asthmatic attack in children, including parents of children who had previously experienced life threatening attacks.

THE FATAL EPISODE

Three children were found dead and details could not be obtained for one child who died while away from home. The length of the final attack in the remaining 31 cases was defined as the time between onset or notable increase in wheezing and cardiorespiratory arrest.

Deaths within three hours of onset $(n=11)$

These children died rapidly: six within 30 minutes of onset and five within three hours. There was avoidable delay in seeking medical help in one case. Two children suffered from permanent wheezing that was difficult to control even on maximal treatment. Four cases were inadequately controlled and their sudden severe attacks might have been prevented by better long term management. Five children were considered to be in reasonable control. Their rapidly fatal attacks occurred without prior warning. Six of the 11 had previously experienced a 'near fatal' attack. Nine of these rapid deaths occurred from 1980 to 1985 inclusive, but these numbers are too small to draw conclusions as to possible changes in the pattern of death with time.

\section{Later deaths $(n=20)$}

Death occurred between six and 72 hours after the onset of the attack (average length 24 hours). In these 20 cases there should have been time for treatment with adequate systemic corticosteroid to have been effective. Only two of these patients, however, had received appropriate amounts of corticosteroid before becoming moribund. Six of the 20 cases were either receiving long term systemic corticosteroid or had recently stopped such treatment. Corticosteroids had neither been increased nor recommenced during the final attack.

Thirteen cases died before reaching the hospital ward: either at home, in transit to hospital, or within 30 minutes of arrival in an accident and emergency department. Six of these children received no treatment over and above their usual oral or inhaled bronchodilator. The seven remaining children were either inadequately treated or were in extremis when the treatment was initiated. Delay or failure to seek medical help had occurred in nine of these 13 cases; in six of the 13, there had been an inappropriate medical response when help had been sought. One general practitioner had failed to attend, one child had been returned home from an accident and emergency department without proper assessment, and four cases were not referred to hospital. 


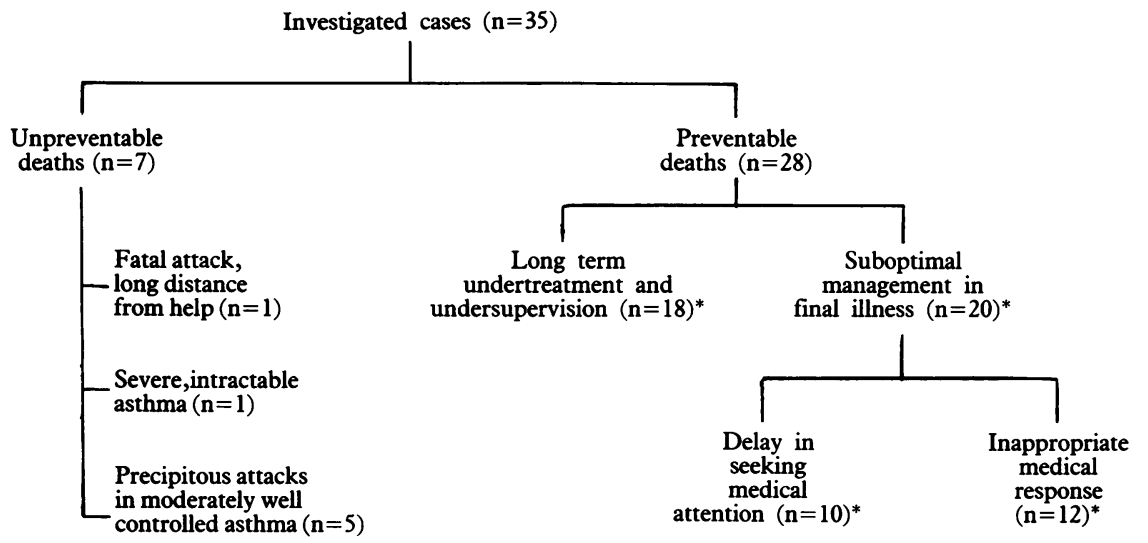

Figure 2 Summary of factors involved in deaths studied. ${ }^{*}$ Factors overlapped in some cases.

There were seven inpatient deaths. Four children died between nine and 20 hours after hospital admission. One child suffered a respiratory arrest 2.5 hours after arrival and died some days later of irreversible brain damage. Two further children died after some weeks of inpatient care for stabilisation. Five hospital deaths occurred in children below 5 years of age, two of whom were diagnosed as 'wheezy bronchitis'.

With hindsight, six of the seven inpatient deaths might have been prevented had there been recognition of the severity of the condition, institution of more aggressive treatment, and possibly ventilation. In four cases systemic corticosteroid had been administered only when death appeared imminent, and bronchodilator treatment was often inadequate.

Despite the failed response to initial treatment and subsequent deterioration in all six cases, blood gas estimation had been performed in only one child.

CONCLUSIONS REGARDING OVERALL MANAGEMENT If the overall care is examined critically then missed opportunities in management are identified in 28 of 35 cases. These factors are summarised in fig 2 .

\section{Discussion}

Our survey suggests that with the knowledge of hindsight a high proportion of childhood asthma deaths are preventable, bearing out the findings of previous studies. ${ }^{3} 4$ In common with these studies, our survey was inevitably retrospective. A criticism of such a survey is the reliance in part on parental recall. However, parents' recollections of prescribed treatment were largely accurate when compared with case records. Most described convincingly the history of their child's symptoms and the effect on daily life and activities. Furthermore, they all recalled the circumstances of the final illness with particular clarity irrespective of how far back the event occurred. It is usual for such a traumatic event to be recalled with accuracy. and infrequent symptoms before the onset of the final illness. Thus the widely held belief that only children with chronic severe asthma are at risk of dying is not true. Nevertheless, a recent controlled study of adult deaths highlighted the prognostic importance of a history of life threatening episodes or recent hospital admission. ${ }^{7}$ With hindsight, half the children in our study were obviously at risk of dying but this fact was insufficiently acknowledged at the time. Hospital discharge letters did not emphasise the life threatening nature of previous attacks, nor were parents properly instructed. Consultants should look critically at 'near miss' asthma deaths in order to take steps to reduce the risk of future fatal outcome.

\section{LONG TERM TREATMENT AND SUPERVISION}

Chronic undertreatment of asthmatic children is well documented and this, ${ }^{8}$ in association with poor supervision, was present in half our cases. They experienced a considerable amount of unnecessary morbidity. Clearly their fatal attacks might not have occurred had closer attention been paid to their long term management. Poor compliance may have influenced control in a few cases but this was impossible to investigate with accuracy. Over-reliance on inhaled bronchodilator was common. In three cases there was chronic over-reliance on home nebulisers. There has been a rapid increase in the use of these since the early 1980s and a number of near fatalities have been reported with their use. ${ }^{910}$ None of our deaths appear to have been related to a direct adverse effect of nebulised treatment, but nebuliser over-reliance in one case had led to fatal delay in seeking further medical help. While they are extremely useful in the home management of children with severe asthma, nebulisers should not be issued without proper education of parents and child and meticulous attention to long term control.

\section{EMERGENCY MANAGEMENT}

The single most important finding was that 20 children who died more than six hours after the onset of the fatal attack had not had access to optimal emergency treatment. The parents con- 
sistently described to us very grave clinical signs but they had not been warned by professionals of the danger of such signs. Some families had become tolerant to severe symptoms while others, despite their anxiety, had been reluctant to call general practitioners at night or weekends. This was reflected by the excess number of weekend deaths. In cases where medical help had been sought, there appeared to have been similar difficulty on the part of professionals in recognising the severity of the condition and the urgent need for appropriate intervention.

\section{PREVENTION OF SEVERE ATTACKS}

Short courses of systemic corticosteroid are standard in the management of severe asthmatic attacks and this was so during the period of study. Work published recently has shown the efficacy of oral corticosteroid in speeding recovery and preventing dangerous deterioration in childhood asthmatic attacks. ${ }^{11} 12$ The use of self initiated courses of oral corticosteroid is accepted practice in the management of adult asthmatics but some paediatricians have tended to be reluctant to apply this to children. Such treatment does not generally cause significant long term hypothalamo-pituitary-adrenal axis suppression. In our analysis we estimated that a parent or patient initiated course of oral corticosteroid might have altered the outcome in at least 20 cases.

\section{RECOMMENDATIONS}

(1) It is imperative that all asthmatic children and their families receive proper education regarding control and self management. Clear written instructions should be provided and reinforced during hospital and practice contacts. Families should be taught how to recognise deteriorating control both clinically and by measurement of peak flow in older children.

(2) Families should have access to a simple method of delivery of bronchodilator in a high dosage to a breathless child, for example, the 'coffee cup' method, or spacer devices. ${ }^{13-15}$

(3) Parents of children receiving inhaled corticosteroid or who have previously suffered a severe attack, should be instructed to initiate a course of oral prednisolone if the attack fails to respond to usual treatment.

(4) Those responsible for the child should know when and how to seek urgent medical help. They should be familiar with danger signs such as breathlessness sufficient to prevent talking, extreme pallor or cyanosis, poor chest movement or increasing lethargy and exhaustion, and should have free access to their local hospital.

(5) Hospitals should have a written management policy for the emergency treatment of children with asthma. This should include early use of systemic corticosteroid.

Implementation of these recommendations would, we believe, contribute to a significant reduction in this unnecessary mortality.

We are grateful to Miss $M$ Trotter for secretarial help and to Drs RAL Brewis and EN Hey for helpful advice.

We gratefully acknowledge financial support from the Northern Child Health Research Fund (CHILD) and Allen and Hanburys Ltd.

1 Research Committee of the British Thoracic Association. Death from asthma in two regions of England. $\mathrm{Br} \mathrm{Med} \mathscr{F}$ 1982;285:1251-5.

2 Sears MR, Rea HH, Beaglehole R, et al. Asthma mortality in New Zealand: a two year national study. NZ Med F 1985; 98:271-5.

3 Sears MR, Rea HH, Fenwick J, et al. Deaths from asthma. Arch Dis Child 1986;61:6-10.

4 Carswell F. Thirty deaths from asthma. Arch Dis Child 1985; 60:25-8.

5 Office of Population Censuses and Surveys. Statistical review of England and Wales 1970-1973. London: HMSO, $1972-1975$.

6 Office of Population Censuses and Surveys. Mortality statistics series. (DH2 Nos 1-12.) London: HMSO, 1977-1987.

. Rea HH, Scragg RT, Jackson R, Beaglehole R, Fenwick J, Sutherland DC. A case control study of deaths from

8 Speight ANP, Lee DA, Hey EN. Under diagnosis and under treatment of asthma in childhood. Br Med $\mathcal{F} 1983 ; 286$ : treatment

9 Lillington AW, Campbell AN, Poulier RA. Safe drugs for childhood asthma? Lancet 1983;ii:1032-3.

10 Kuzemko JA. Near miss asthma deaths in children. Lancet 1985;i:49.

11 Deshpande A, McKenzie SA. Short course of steroids in home treatment of children with acute asthma. $\mathrm{Br} \mathrm{Med} \mathcal{F}$ 1986; 293:169-71.

12 Storr J, Barry W, Barrell E, Lenney W. Effect of a single oral dose of prednisolone in acute childhood asthma. Lancet 1987;i:879-82.

13 Henry RL, Milner AD, Davies JG. Simple drug delivery system for use by young asthmatics. $\mathrm{Br}$ Med $\mathcal{f} 1983$; 286:2021.

14 Pool JB, Greenough A, Gleeson JGA, Price JF. Inhaled bronchodilator treatment via the nebuhaler in young bronchodilator treatment via the nebuhaler in

15 Freelander M, Van 'Asperen PP. Nebuhaler versus nebuliser in children with acute asthma. Br Med $\mathcal{J}$ 1984;288:1873-4. 